\title{
New collection locality of Cryptotis tropicalis (Merriam, 1895) (Eulipotyphla: Soricidae) in the south lowlands of Guatemala, Central America
}

\section{Cristian Kraker-Castañeda}

Departamento de Conservación de la Biodiversidad, El Colegio de la Frontera Sur, 29290, San Cristóbal de Las Casas, Chiapas, Mexico. ckraker@ecosur.edu.mx

Unidad para el Conocimiento, Uso y Valoración de la Biodiversidad, Centro de Estudios Conservacionistas, Universidad de San Carlos de Guatemala, 01010, Guatemala City, Guatemala

\section{Lázaro Guevara}

Departamento de Biología Evolutiva, Facultad de Ciencias, Universidad Nacional Autónoma de México, 04510, Mexico City, Mexico

\section{Consuelo Lorenzo}

Jorge Bolaños-Citalán

Departamento de Conservación de la Biodiversidad, El Colegio de la Frontera Sur, 29290, San Cristóbal de Las Casas, Chiapas, Mexico Elida M. Leiva-González

Escuela de Biología, Facultad de Ciencias Químicas y Farmacia, Universidad de San Carlos de Guatemala, 01012, Guatemala City, Guatemala

The shrews in the genus Cryptotis (Eulipotyphla: Soricidae) reach highest species richness in southern Mexico and northern Central America (Woodman 2010, Woodman et al. 2012). They are often found at medium to high elevations, and confined to moist areas (Woodman \& Timm 1992, Woodman et al. 2012). Two notable exceptions are C. lacandonensis Guevara et al., 2014 and C. mayensis (Merriam, 1901), which are restricted to lowlands (Woodman 2010, Guevara et al. 2014).

Cryptotis tropicalis (Merriam, 1895) belongs to the C. parvus-group, and it was previously recognized as a subspecies (Whitaker 1974, Choate 1970). Its distribution range extends from the eastern highlands of Chiapas (southeast Mexico), to Belize and Guatemala (Goodwin 1934, Hutterer 2005, Woodman 2008), and it has been estimated to occur at elevations between 975 to $1.580 \mathrm{~m}$ asl (Woodman et al. 2012), and 444 to $1.594 \mathrm{~m}$ asl (Guevara et al. 2015), which suggests inaccurate information. This species is confirmed from only few and scattered collection localities, and it is listed as Data Deficient by the IUCN Red List of Threatened Species (Woodman 2008). It is considered understudied, lacking information on its ecological requirements, population trends, and conservation status (Woodman 2008). Here, we describe a new collection locality based on a specimen caught at the southernmost edge of its distribution range.

In January 2013, we carried out a mammal inventory in the south lowlands of Guatemala (elevation below $500 \mathrm{~m}$ ), in the south slope of the Tecuamburro Volcano, in Taxisco, Santa Rosa. The area is immersed in Subtropical Very Wet Forest (Castañeda 2008). We captured a male adult shrew in a pitfall container located within a riparian forest, following the river bank locally known as El Pajal, at $410 \mathrm{msnm}(14,119 \mathrm{~N},-90,505 \mathrm{~W})$. The specimen was collected, and prepared as dried skin and skull following the protocols of The Animal Care and Use Committee (Gannon et al. 2007). As a collaboration agreement, it was housed as voucher in the Mammals Collection of El Colegio de la Frontera Sur, San Cristóbal de Las Casas, Mexico (ECO-SC-M 4637).

The specimen belonged to the genus Cryptotis, which was recognized by a tail less than $50 \%$ of the length of the body, and short ears covered with hair (Carraway 2007, Álvarez-Castañeda et al. 2015). It displayed a distinctly paler ventral pelage contrasting noticeably with the dorsal pelage, feature that may help distinguish $C$. tropicalis (our first taxonomic guess) from other species (see Woodman 2011a). Selected external measurements were taken in field with a digital caliper (Mitutoyo ${ }$, Illinois, US), to the nearest $0,01 \mathrm{~mm}$ : total length 69 ; tail length 16,4; hind foot length 9,4. Selected skull measurements were taken in laboratory with a digital caliper (Mitutoyo ${ }^{\circledR}$, Illinois, US), under a stereomicroscope, to the nearest $0,01 \mathrm{~mm}$ : condylobasal length 16,81 ; palatal length 7,31 ; interorbital breadth 4,14 ; cranial breadth 8,47 ; zygomatic plate breadth 1,44 . 
Cryptotis tropicalis can be differentiated from other small-eared shrews present in the country, specifically representatives of the C. goldmani-group (i.e., C. mam, C. goodwini, C. oreoryctes, C. lacertosus), based on its much smaller body size (see Woodman 2011b). Although some measurements of $C$. tropicalis might overlap with those of representatives of the $C$. nigrescens-group present in the country, such as C. mayensis and C. merriami, the former is known in the country from a single modern collection in the northern lowlands (which represents the southwestern limit of its distribution range), and the latter is known to occur starting from $600 \mathrm{~m}$, but it exhibits larger selected measurements (e.g., condylobasal length of skull) (see Woodman et al. 2012). It is important to notice that our record is close to the eastern geographic limit estimated for $C$. tropicalis, as well as the western geographic limit estimated for $C$. orophila; the latter, is present further down east in El Salvador and Honduras, and not yet known in Guatemala (Woodman et al. 2012).

Once we verified the identity, we compiled a geographic database since the beginning of the $20^{\text {th }}$ century to the specimen collected in 2013 based on specialized literature, mammal collections, and the Global Biodiversity Information Facility (http://www.gbif.org/; Appendix 1). We georeferenced the unique previous record in the south lowlands of the country (AMNH 244327) based on its locality description, using a geographical gazetter (http://www.fallingrain.com). We projected the records on a map (Figure 1), and included the distribution range of this species according to the International Union for Conservation of Nature (Woodman 2008). We obtained the elevation data whenever missing from the collections' information, using global climate layers (Hijmans et al. 2005), specifically of WorldClim v. 1.4 (http://www.worldclim.org). We extracted the data from ESRI grids (30 arc-seconds spatial resolution), using ArcView v. 3.2 (ESRI, Inc., USA). Finally, for each collection locality we extracted and plotted mean annual temperature and annual precipitation data, in order to complement the environmental information (Figure 2).

$-92$

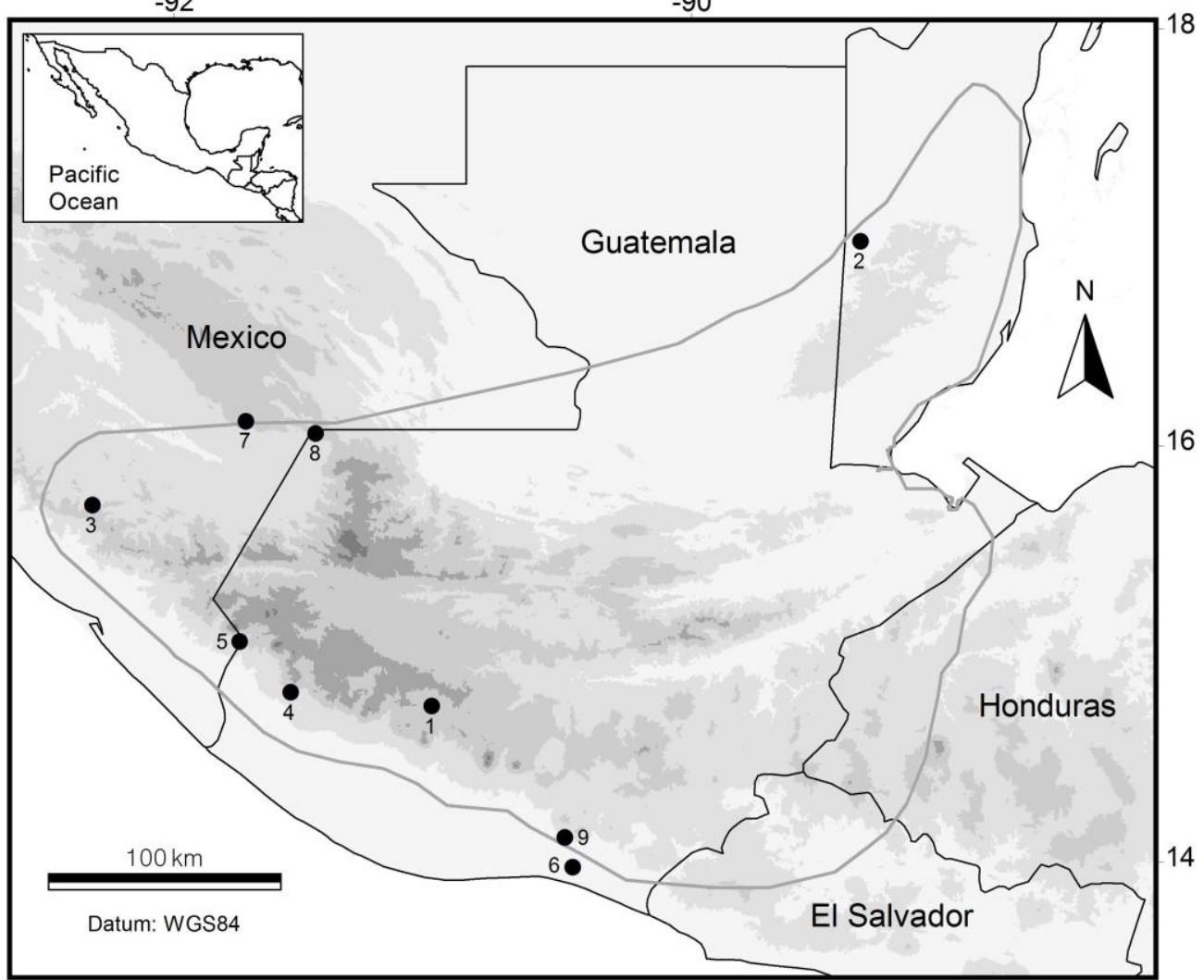

Figure 1. Confirmed collection localities of Cryptotis tropicalis (Merriam, 1895) since the beginning of the $20^{\text {th }}$ century, to the specimen collected in 2013. The records in the south lowlands of Guatemala are indicated with the following numbers: AMNH 244327 (6), ECOSC-M 4637 (9) (for more details see Appendix 1). 


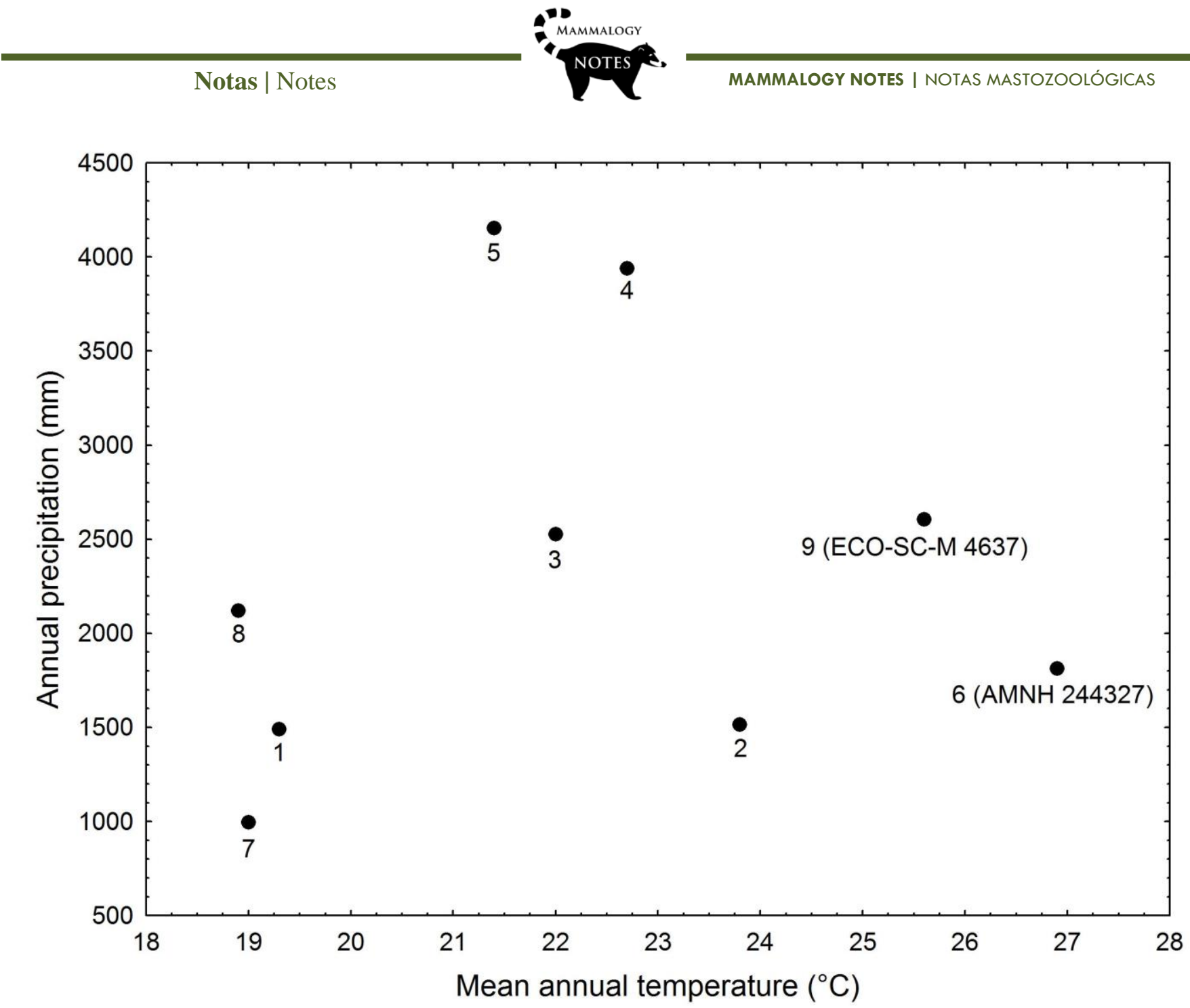

Figure 2. Biplot with mean annual temperature and annual precipitation data extracted from global climate layers for confirmed collection localities of Cryptotis tropicalis (Merriam, 1985). The records for the southern lowlands of Guatemala are indicated with the following numbers: AMNH 244327 (6), ECO-SC-M 4637 (9) (for more details see Appendix 1).

Based on our geographical prospection, we were able to determine that $C$. tropicalis can be present starting close to sea level as inferred by elevation data $(\sim 19 \mathrm{~m}$ asl) to high elevations $(1.580 \mathrm{~m}$ asl; Woodman et al. 2012). Specifically, the records in the south lowlands of the country turned out to fall below the elevation limits previously estimated in literature (see Guevara et al. 2015, Woodman et al. 2012). In the south lowlands of the country, the time interval between our collection and the previous geographically closest one (from 37 years ago), their spatial proximity $(\sim 16,5 \mathrm{~km})$, as well as the characteristic land use in the surroundings (i.e., cultivated grasslands and sugarcane crops), allow us to suggest that populations of $C$. tropicalis may be resilient while facing environmental disturbance, as previously noted by Woodman et al. (2012). Nevertheless, in this area, the trend is towards the transformation of large extensions of land, while forests are being lost (see INAB et al. 2012), posing an important threat to biodiversity.

\section{Acknowledgements}

We would like to thank G. Ruano for the invitation to the faunal survey. We are also grateful to N. Woodman, N. Ordóñez, and E. Westwig for their specialized scientific advice. We thank M. Ruiz for the language revision, and D. Marin for his valuable comments that helped improved this manuscript. 


\section{References}

Álvarez-Castañeda, S. T., et al. 2015. Key for identifying mammals of Mexico in the field and in the laboratory. Centro de Investigaciones Biológicas del Noroeste S. C., Laboratorio de Cordados Terrestres de la Escuela Nacional de Ciencias Biológicas, Universidad Autónoma Metropolitana. Mexico.

Carraway, L. 2007. Shrews (Eulypotyphla: Soricidae) of Mexico. Monographs of the Western North American Naturalist 3: 1-91.

CASTAÑEDA, C. 2008. Diversidad de ecosistemas de Guatemala. Pp 181-229 in Guatemala y su biodiversidad: un enfoque histórico, cultural, biológico y económico (Azurdia C, et al., eds.), Consejo Nacional de Áreas Protegidas, Guatemala City, Guatemala.

CHOATE, J. 1970. Systematics and zoogeography of the Middle American shrews of the genus Cryptotis. University of Kansas, Museum of Natural History $19: 195-317$.

GANNON, W. L., et al. 2007. Guidelines of The American Society of Mammalogists for the use of wild mammals in research. Journal of Mammalogy 88(3): 809-823.

Goodwin, G. G. 1934. Mammals collected by A W. Anthony in Guatemala, 1924-1928. Bulletin of the American Museum of Natural History 68: 1.

GuevarA, L., et al. 2014. A new species of small-eared shrew (Mammalia, Eulipotyphla, Cryptotis) from the Lacandona rain forest, Mexico. Journal of Mammalogy 95(4): 739753.

GuEvarA, L., et al. 2015. Species richness, distribution, and conservation of moles and shrews (Mammalia, Eulipotyphla) from Mexico. Therya 6(1): 43-68.

HiJMANS, R. J., et al. 2005. Very high-resolution interpolated climate surfaces for global land areas. International Journal of Climatology $25(15)$ : $1965-1978$.

HUTTERER, R. 2005. Order Soricomorpha. Pp 220-231 In Mammal species of the world: a taxonomic and geographic reference (Wilson D \& D Reeder, eds.), Third edition, Smithsonian Institution Press, Washington D. C., USA.

INAB (Instituto NACIONAL De BosQUeS), et al. 2012. Mapa de cobertura forestal de Guatemala 2010 y dinámica de la cobertura forestal 2006-2010. Instituto Nacional de Bosques, Consejo Nacional de Áreas Protegidas, Universidad del Valle de Guatemala, Universidad Rafael Landívar. Guatemala.

WhITAKeR JR., J. O. 1974. Cryptotis parva. Mammalian Species 43: 1-8.

Woodman, N. \& R. M. TIMM. 1992. A new species of small-eared shrew, genus Cryptotis (Insectivora: Soricidae) from Honduras. Proceedings of the Biological Society of Washington 105(1): 1-12.

Woodman, N. 2008. Cryptotis tropicalis. The IUCN Red List of Threatened Species 2008: e.T136757A4336006

WoOdMAN, N. 2010. Two new species of shrews (Soricidae) from the western highlands of Guatemala. Journal of Mammalogy 91(3): 566-579.

Woodman, N. 2011a. Nomenclatural notes and identification of small-eared shrews (Mammalia: genus Cryptotis) from Cobán, Guatemala, in The Natural History Museum, London. Proceedings of the Biological Society of Washington 124(4): 249-258.

Woodman, N. 2011b. Patterns of morphological variation amongst semifossorial shrews in the highlands of Guatemala, with the description of a new species (Mammalia, Soricomorpha, Soricidae). Zoological Journal of the Linnean Society 163: 1267-1288.

Woodman, N., et al. 2012. Distributional records of shrews (Mammalia, Soricomorpha, Soricidae) from northern Central America with the first record of Sorex from Honduras. Annals of the Carnegie Museum 80(3): 207-237.

\section{Appendix 1.}

Confirmed collection localities of Cryptotis tropicalis (Merriam, 1895) since the beginning of the $20^{\text {th }}$ century, to the specimen collected in 2013. The numbering in parentheses corresponds chronologically to the projected geographic coordinates in Figure 1. The asterisk denotes data extracted from an elevation grid. (1) GUATEMALA: Panajachel, Sololá, 1926, 14,75, -91,15, 1.493,52 m (AMNH 74295-74301).- (2) BELIZE: Mountain Pine Ridge, 20,2 km S Cayo, Cayo District, 1931, 16,9816, -89,071389, 444 m* (UMMZ 63008-63011).- (3) MEXICO: Finca Prusia, Reserva de la Biósfera El Triunfo, Ángel Albino Corzo, Chiapas, 1944, 15,716, -92,794, 1.110 m (CNMA 18, 170).- (4) GUATEMALA: Finca La Paz, La Reforma, San Marcos, 1957, 14,817, -90,833, 1.111 m* (UMMZ 108488, 108489).- (5) MEXICO: Barranca de Río Malá, Volcán Tacaná, Unión Juárez, Chiapas, 1960, 15,061, -92,081, 1.284 m* (CNMA 9063).- (6) GUATEMALA: 6 km N La Avellana, Taxisco, Santa Rosa, 1976, 13,97, -90,46, 19 m* (AMNH 244327).- (7) MEXICO: La Trinitaria, Chiapas, 1985, 16,117778, -92,052, 1.559 m* (CNMA 36461-36471).- (8) GUATEMALA: 3.5 km N Aldea La Trinidad, Nentón, Huehuetenango, 2009, 16,058333, -91,714, 1.580 m (USNM 570435).- (9) GUATEMALA: Finca Tacuilula, Taxisco, Santa Rosa, 2013, 14,119, -90,505, 410 m (ECO-SC-M 4637). Abbreviations. AMNH = American Museum of Natural History, New York, USA; UMMZ = Museum of Zoology, University of Michigan, Michigan, USA; CNMA = Colección Nacional de Mamíferos, Instituto de Biología, Universidad Nacional Autónoma de México, Mexico; USNM = National Museum of Natural History, Washington, USA; ECO-SC-M = Mammal Collection, El Colegio de la Frontera Sur, San Cristóbal de Las Casas, Mexico. 